\title{
Deconstructing bathymetric body size patterns in deep-sea gastropods
}

\author{
Craig R. McClain ${ }^{1, *}$, Michael A. $\operatorname{Rex}^{2}$, Randa Jabbour ${ }^{3}$ \\ ${ }^{1}$ Biocomplexity Working Group, Biology Department, University of New Mexico, Albuquerque, New Mexico 87131, USA \\ ${ }^{2}$ Biology Department, University of Massachusetts Boston, Boston, Massachusetts 02125, USA \\ ${ }^{3}$ Intercollege Graduate Degree Program in Ecology, Pennsylvania State University, University Park, Pennsylvania 16802, USA
}

\begin{abstract}
Attempts to understand body size as an adaptation to the deep sea have relied primarily on measuring and interpreting size-depth relationships. The numerous studies documenting bathymetric size trends during the last 30 yr report widely divergent results. Body size has been found to significantly increase or decrease with depth in different taxa, but often shows no statistical pattern. Some of this variation is attributable to methodological inconsistencies and/or differences in how taxa or functional groups respond to environmental gradients associated with depth. Here, we show that the shape of the size-depth relationship also depends on the depth zone inhabited. We measured shell size for gastropods (81 species, 3423 individuals) collected in the western North Atlantic from depths of 200 to $5000 \mathrm{~m}$. This database makes it possible to assess size within species and among taxa, and to document how body size changes across the continental margin and abyssal plain. Quantile regression shows that maximum size attained among all gastropods increases with depth in the bathyal zone, and then decreases in the abyss. This overall unimodal pattern appears to be generated partly by within-species clines. Size tends to increase with depth in species with upperto mid-bathyal distributions, and to decrease with depth in species with lower-bathyal to abyssal distributions, independent of feeding type and mode of larval development. The shift from predominantly positive to negative specific size-depth clines at the bathyal-abyssal transition and the prevalence of smaller individuals in the abyss may reflect a fundamental change in ecological opportunity.
\end{abstract}

KEY WORDS: Benthic $\cdot$ Productivity $\cdot$ Source-sink dynamics $\cdot$ Quantile regression $\cdot$ Western North Atlantic $\cdot$ Deep sea $\cdot$ Body size

Resale or republication not permitted without written consent of the publisher

\section{INTRODUCTION}

No potentially adaptive property of deep-sea organisms has received more attention than body size. Since many physiological and life-history features scale with body size (Peters 1983, Brown 1995, Gillooly et al. 2001, 2002, Savage et al. 2004), comparative studies of size may help reveal the connection between the biodiversity of communities and the evolved characteristics of their constituent species. Since Thiel (1975, 1979) first demonstrated that the average size of organisms decreases with depth in the deep sea, a large literature on bathymetric patterns of body size has developed (reviewed in Rex \& Etter 1998). Nearly all of these studies examine depth trends in the average size of whole functional groups or higher taxa. The results are highly disparate, owing in part to methodological differences, and presumably to real biological differences in how faunal groups respond to depth gradients (Rex \& Etter 1998).

The relationship between average size and depth depends on either variation within species or depthrelated replacement of species that differ in size. Since adaptation is a property of species, not communities, the explanation of depth trends in average size ultimately must be sought at the species level. There have been very few measurements of size-depth patterns within deep-sea macrofaunal species. Among gastro- 
pod species, the size-depth clines that have been examined are mostly positive (Rex \& Etter 1998, Rex et al. 1999, Clain \& Rex 2000, McClain \& Rex 2001) or insignificant, but negative patterns are known (Olabarria \& Thurston 2003, this study). Roy (2002) found a variety of size-depth trends in gastropod families on the continental shelf of the eastern North Pacific.

In the present study, we document size-depth patterns within and among gastropod species using a greatly expanded database of individuals and species, and more equable depth coverage. Size-depth trends change gradually from positive to negative with increasing depth. This shift appears to be related to processes that also regulate biodiversity in bathyal and abyssal regions.

\section{MATERIALS AND METHODS}

To obtain a more comprehensive picture of sizedepth trends, we combined 2 existing databases on turrid neogastropods (Rex et al. 1999, Clain \& Rex 2000) with new measurements of shell dimensions on 2809 additional individuals from 70 caenogastropod and vetigastropod species. If samples for individual species at a site exceeded 100, we selected 50 individuals at random to measure. In total, the material analyzed represents 3423 individuals distributed among 81 species. The samples were collected using epibenthic sleds (Hessler \& Sanders 1967) and anchor dredges (Sanders et al. 1965) from depths of 196 to $5042 \mathrm{~m}$ south of New England (Fig. 1) as part of the Woods Hole Oceanographic Institution's Benthic Sampling Program (Sanders 1977). Analyses of trophic roles and modes of larval development in the assemblage can be found in Rex (1976) and Rex \& Warén (1982).

Images of all prosobranch shells were obtained from a Spot TR digital camera mounted to a Nikon SMZ1000 dissection scope. Digital images were analyzed and imaged on a Macintosh G4 using Spot Advanced software. Shell size was measured as maximum height plus maximum width, with the shell in standard orientation as described by Rex et al. (1999). The relationship between size and depth was examined with quantile regression (Scharf et al. 1998, Cade et al. 1999, Cade \& Noon 2003) using the statistical software pack-

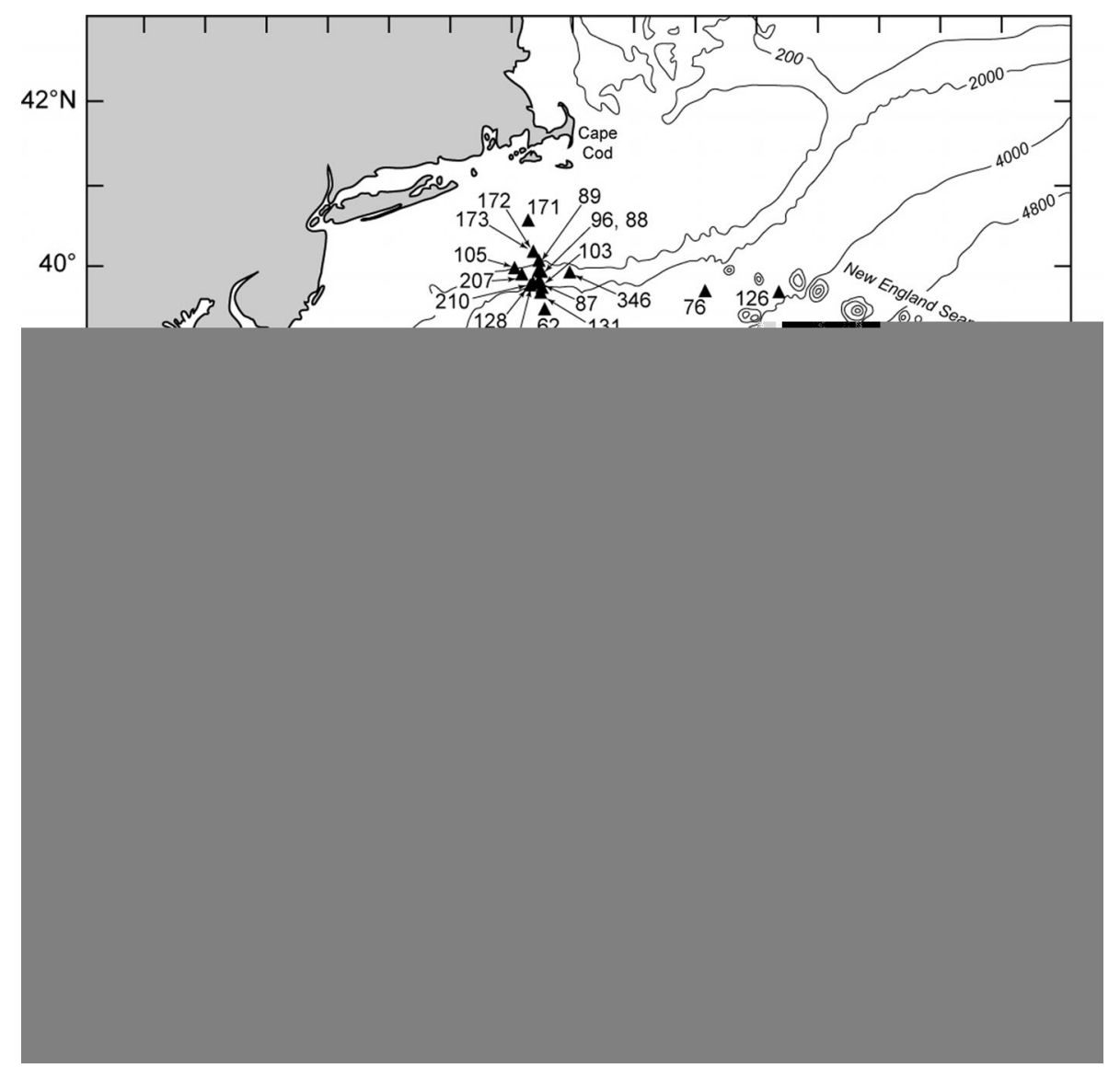

Fig. 1. Map of sampling localities in the Northwest Atlantic Ocean used to assess bathymetric patterns of shell size 
age BLOSSOM ${ }^{\mathrm{TM}}$, developed by the Midcontinental Ecological Science Center. Most theories of optimal size predict the size at which animals stop growing (Sebens 1987, Chapelle \& Peck 1999), and quantile regression provides a way to detect trends in final size without sacrificing other information on the distribution of size (McClain \& Rex 2001). Throughout the paper, we refer to the largest size attained per depth as maximum size. We explored 99, 95, 90 and $85 \%$ quantile regressions for relationships of size to depth. We report the 99, 95 and $90 \%$ quantiles for the relationship of individual size to depth using all gastropods measured. For size-depth clines in individual species, we report the $85 \%$ quantile, which showed the greatest number of significant relationships.

\section{RESULTS AND DISCUSSION}

The interspecific analysis of all gastropod individuals shows a unimodal pattern of size with depth (Fig. 2). Size increases to around $3000 \mathrm{~m}$ in the bathyal zone, and then decreases toward the abyss. We used parabolic quantile regressions to describe this pattern because they explain considerably more variance (about 20\%) than linear regressions (about 2 to $5 \%$ ). The increase in size across the bathyal region essentially corroborates earlier findings (Rex \& Etter 1998, Rex et al. 1999, Clain \& Rex 2000, McClain \& Rex
2001). The reduction of size in the abyss had not been observed because of the paucity of abyssal data in the North Atlantic, although Harasewych \& Kantor (2004) recently showed that the average size of buccinoidean snails decreases from bathyal to abyssal depths in the Scotia Sea off Antarctica. Interestingly, there is, in hindsight, a clear suggestion in our earlier published data that the maximum sizes of abyssal populations are lower (see Rex et al. 1999, Fig. 2 bottom, and McClain \& Rex 2001, Fig. 1a); but it was not statistically supported and was dismissed as an artifact. A similar trend is observed in some megafaunal elements of the deep western North Atlantic (Polloni et al. 1979).

A more intuitive way of visualizing the pattern is shown in Fig. 3. The relative abundance distributions of individuals in size classes are plotted for successive $1000 \mathrm{~m}$ depth intervals. Normal curves are fitted to the distributions and the vertical dashed lines approximate the $95 \%$ quantile for the data in each depth bin. Both the central tendency of size and maximum size increase to a peak in the 2000-3000 m interval and then decline toward the abyss. The changes in average size among the size distributions are significant (Kolmogorov-Smirnov test at the $\alpha=0.05$ level) except between the shallowest $(0-1000 \mathrm{~m})$ and deepest (5000-6000 m); and between 4000-5000 and 5000-6000 $\mathrm{m}$, the latter of which is a seaward extension in the abyssal plain representing few data (Fig. 2).

Fig. 2. Quantile regression plots of the relationship between maximum size and depth for all individuals $(\mathrm{N}=$ $3423, \mathrm{~S}=81) . \mathrm{R}_{1}=0.1982,0.2052$, and 0.2022 for 99,95 , and $90 \%$ quantiles, respectively; $\mathrm{p}=0.0002$ for all quantiles. Regression equations for $99 \%$ : $y=1.831+0.019 x-0.000003 x^{2}, 95 \%$ : $y=2.178+0.012 x-0.000002 x^{2} ; 90 \%$ : $y=2.045+0.009 x-0.000002 x^{2}$

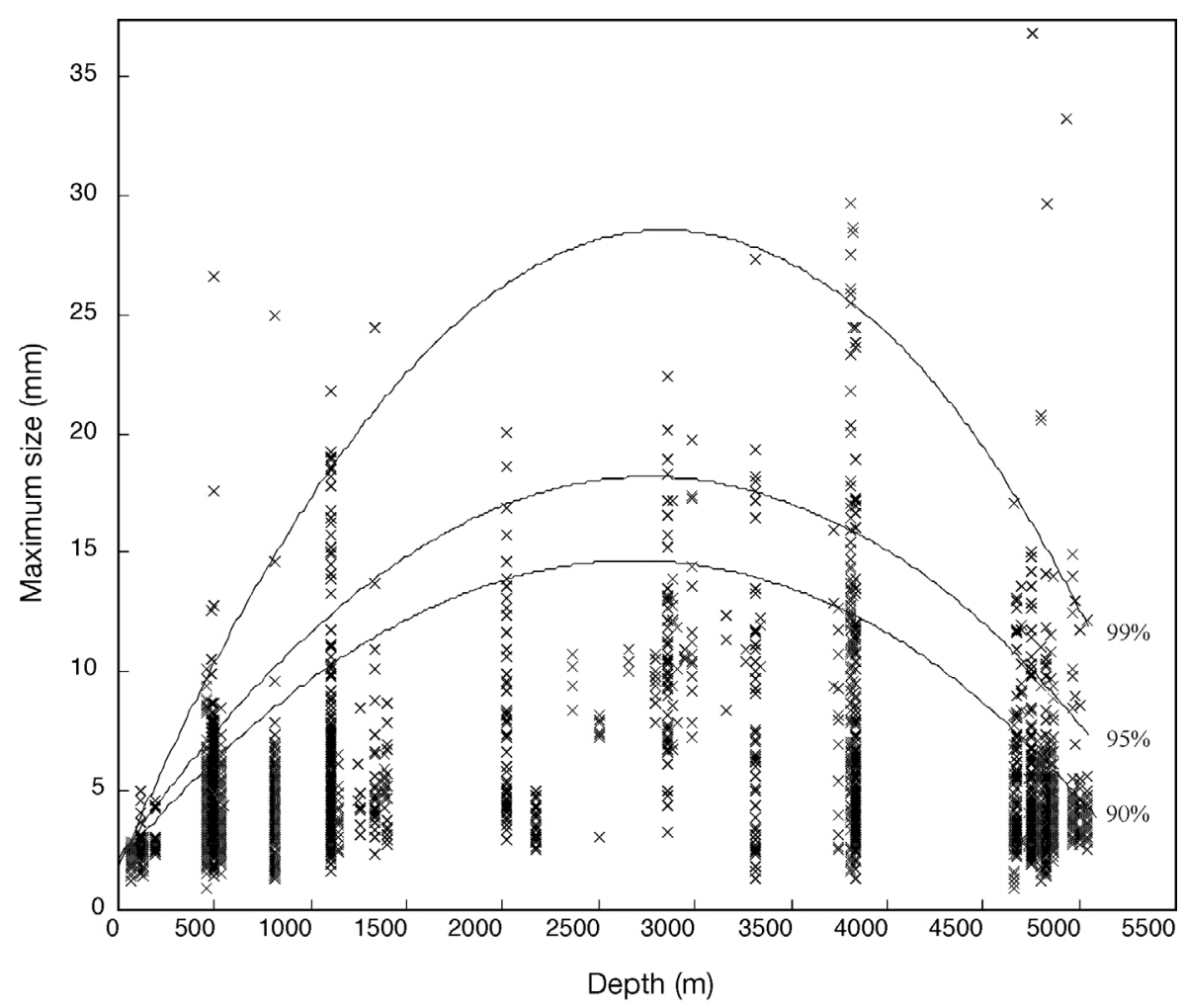


In Fig. 4, we plot size-depth clines for 17 species that have significant relationships at the $85 \%$ level, the quantile with the greatest number of significant regressions. The general pattern is that slopes of the regressions are primarily positive in the bathyal zone and tend to become negative in the lower bathyal and abyssal regions, although positive and negative slopes are found in all areas. When the species are divided

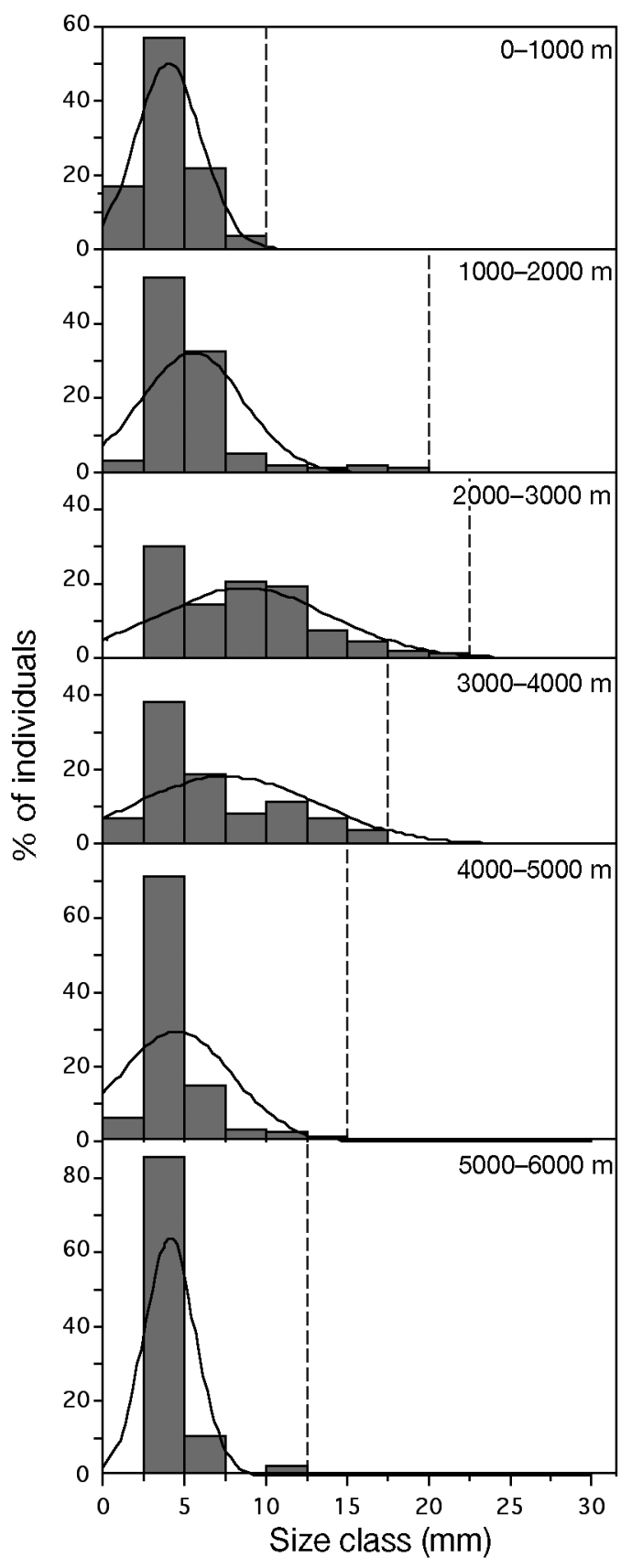

Fig. 3. Percentage of individuals in $5 \mathrm{~mm}$ size classes for $1000 \mathrm{~m}$ depth intervals. Black lines are normal curves fitted to the data and dashed lines indicate the size class corresponding to the upper $95 \%$ quantile into 2 depth groups - those with ranges that are mostly bathyal (Op, Mp, Tm, Ph, Ac, Ce, Cb, Ba, Ta and Ps in Fig. 4) and those that are mostly lower bathyal and abyssal ( $\mathrm{Tl}, \mathrm{By}, \mathrm{Gy}, \mathrm{Pl}, \mathrm{Dp}, \mathrm{Bt}, \mathrm{Se}$ in Fig. 4) - there is a significant shift in the sign of the size-depth slopes from more positive to more negative $\left(\chi^{2}=5.130\right.$, df $=1, p=0.0235$; the more conservative Fisher-Yates exact probability $=0.0498$ ). The sign is unrelated to feeding type (predator vs. deposit feeder, $\chi^{2}=1.431, \mathrm{df}=1, \mathrm{p}=0.2316$ ) and to mode of larval development (dispersing vs. nondispersing, $\chi^{2}=2.837$, $\mathrm{df}=1, \mathrm{p}=0.0921$ ). Information on feeding types, larval dispersal, and definitions of species abbreviations are provided in Table 1.

Variation in maximum size as a function of depth within species generally agrees with earlier analyses based on fewer species that were primarily bathyal in distribution and used different measures of size (Rex \& Etter 1998). Earlier analyses (e.g. Etter \& Rex 1990, Rex \& Etter 1990) were directed at documenting patterns of geographic variation in shell phenotypic traits (size, shape, sculpture) that required using measurements standardized to common growth stages in order to avoid the potentially confounding effects of differences in allometry. These studies attempted to identify regions of evolutionary population differentiation. Later studies, including this one, are concerned with assessing maximum size attained because this is the variable predicted by ecological models of optimal size (Sebens 1982, 1987). The lower-bathyal and abyssal Benthonella tenella, which previously showed no significant bathymetric trend for size standardized to a common growth stage (end of first adult whorl), reveals a significant negative pattern with depth for maximum size when considerably larger sample sizes are included (Fig. 4). Mitrella pura formerly showed a positive trend for standardized size, and now shows a negative trend for maximum size. Frigidoalvania brychia showed a positive relationship for standardized size, but no significant trend for maximum size despite the fact that standardized size and maximum size are correlated (Rex \& Etter 1998). Clearly the measure of size used and sample size can matter, and the addition of more lower-bathyal and abyssal material here shows that size-depth relationships change from positive to negative at the base of the continental margin both within and among species (Fig. 4).

The much expanded data and analyses presented here modify our view of size-depth trends in North Atlantic deep-sea gastropods. Initial studies, based largely on bathyal data and many fewer species (Rex \& Etter 1998, Rex et al. 1999, Clain \& Rex 2000, McClain $\&$ Rex 2001), gave the impression that size increased consistently with depth both within and among species. Apart from the upper bathyal species Troschelia 


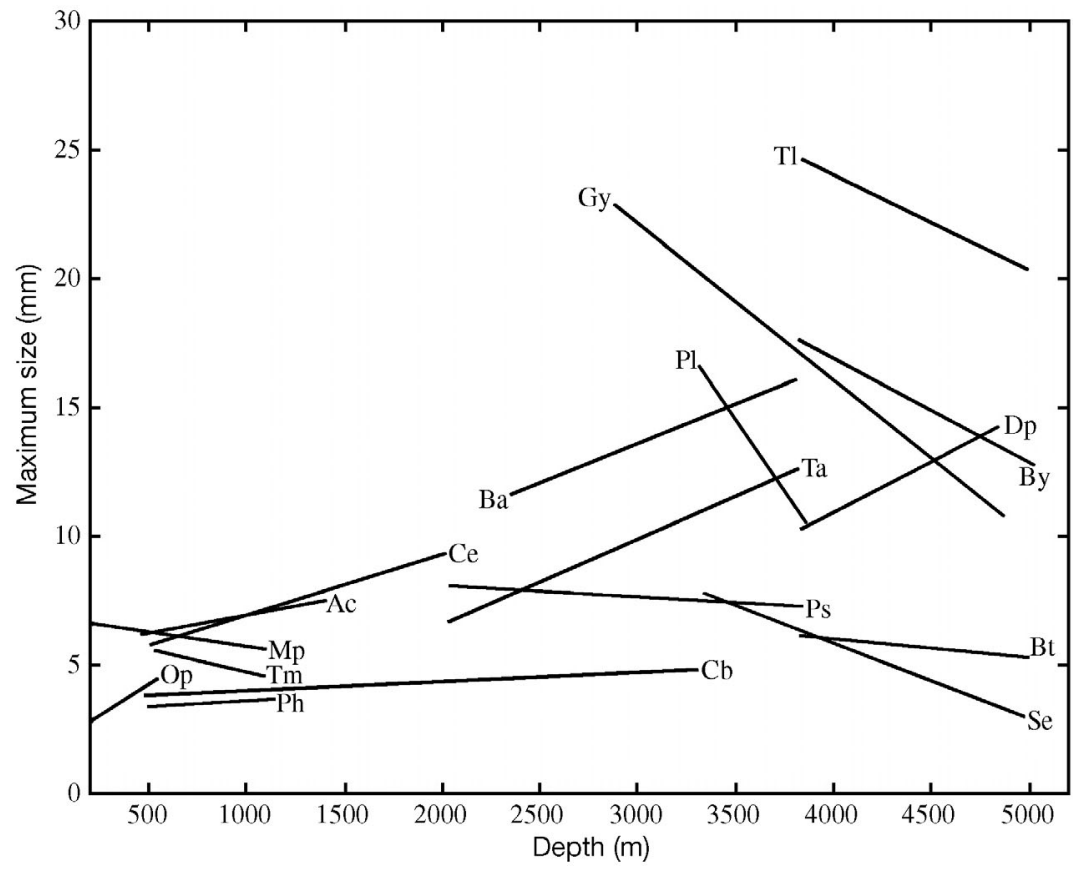

Fig. 4. Eighty five percent quantile regression plot of the relationship between maximum size and depth for abundant species of prosobranch gastropods in the Northwest Atlantic Ocean. Only significant regression lines are shown. Information on feeding types, larval dispersal, and definitions of species abbreviations are provided in Table 1

berniciensis in the eastern Atlantic (Olabarria \& Thurston 2003), there was previously no indication that size decreases with depth. It is now apparent that the predominant pattern seems to be an increase across the bathyal zone and then a decline at abyssal depths.

The within-species trends (Fig. 4) are reflected in the overall pattern for all gastropods (Figs. 2 \& 3), suggesting that intraspecific clinal variation exerts an important influence on size-depth trends. This does not deny the possibility that changes in average size (Fig. 3) reflect species replacement with depth as proposed by Lampitt et al. (1986) and Jumars \& Wheatcroft (1989). Gastropods do have a high rate of species replacement with depth (Rex 1977). To test for a speciesreplacement component, we regressed the average size of individual species against the mid-points of their depth ranges for all species that did not show significant clinal effects (64 species). We detected no significant size-depth relationships using either least-square linear and quadratic methods or quantile $(90,95$, $99 \%)$ linear and quadratic methods $(\mathrm{p}=0.11-0.89)$.
The general agreement of clinal patterns (Fig. 4) with the overall size-depth distribution (Figs. 2 \& 3) suggests that size is an evolutionary adaptive response to an environmental gradient in the deep sea. This point may seem implicit and obvious, but most studies of size-depth relationships in deep-sea organisms are either interpreted in terms of ecological energetics, or simply assume that size is adaptive without providing within-species evidence for geographic variation. Of course, it is important to recognize that not all geographic variation in size need be adaptive-it could also be a phenotypic plastic response (Van Voorhies 1996). Deep-sea mollusks show strong depthrelated clinal variation in shell architecture (Etter \& Rex 1990) and genetic population structure (Chase et al. 1998, Etter et al. 2005), but the genetic basis of size is not known.

The increase in maximum size attained with depth in bathyal snails has been attributed to increasing metabolic and competitive advantages of larger size as food resources diminish (Rex \& Etter 1998, Rex et al. 1999). Larger organisms have a more efficient metabolic rate per unit weight that can maximize standing stock, although metabolic advantages can be offset by inverse density dependence at low density in a food-limited environment like the deep sea (Thiel 1975). Optimality models of body size in marine invertebrates (Sebens 1982,1987) predict that size should

Table 1. Feeding and larval types for species included in Fig. 4

\begin{tabular}{|lccc|}
\hline Species & Abbreviation & Feeding type & Larval type \\
\hline Onoba pelagica & $\mathrm{Op}$ & Deposit feeder & Nondispersing \\
Mitrella pura & $\mathrm{Mp}$ & Predator & Nondispersing \\
Taranis morchii & $\mathrm{Tm}$ & Predator & Nondispersing \\
Pusilina harpa & $\mathrm{Ph}$ & Deposit feeder & Nondispersing \\
Admete contabulata & $\mathrm{Ac}$ & Predator & Nondispersing \\
Cerithiella sp. & $\mathrm{Ce}$ & Deposit feeder & Nondispersing \\
Benthomangelia antonia & $\mathrm{Ba}$ & Predator & Dispersing \\
Gymnobela sp. & $\mathrm{Gy}$ & Predator & Dispersing \\
Pleurotomella lottae & $\mathrm{Pl}$ & Predator & Dispersing \\
Cylclostrema basistriatum & $\mathrm{Cb}$ & Deposit feeder & Dispersing \\
Theta lyronuclea & $\mathrm{Tl}$ & Predator & Dispersing \\
Trophon abyssorum & $\mathrm{Ta}$ & Predator & Nondispersing \\
Pleurotomella sandersoni & $\mathrm{Ps}$ & Predator & Dispersing \\
Drilliola pruina & $\mathrm{Dp}$ & Predator & Dispersing \\
Benthobia tyroni & $\mathrm{By}$ & Predator & Dispersing \\
Benthonella tenella & $\mathrm{Bt}$ & Deposit feeder & Dispersing \\
Sequenzia eritima & $\mathrm{Se}$ & Deposit feeder & Dispersing \\
\hline
\end{tabular}


decrease along gradients of decreasing food availability because lower rates of nutrient input depress energy intake and elevate the cost of foraging (Rex \& Etter 1998). This may account for the decrease in average size of benthic animals with depth (Thiel 1979, McClain et al. 2005). However, within species, adaptive tradeoffs are complex, and competing selective factors can shift populations away from an optimal size predicted solely on the basis of energy allocation to reproduction. For example, larger size may enhance competitive ability, reduce mortality from predation and increase the ability to exploit a broader range of food items as resources become scarcer (Levinton 1987, Sebens 1987). Larval size also increases with depth, and the relationship is especially strong in bathyal populations (Rex \& Etter 1998). Larger size at hatching or settlement confers several advantages in marine snails (Spight 1976), including escape from predators, less susceptibility to starvation, greater locomotion for foraging, and a larger range of potential food items.

Clearly the simple explanations for how metabolic and competitive advantages of larger size account for positive size-depth trends in bathyal snails cannot be extended to the abyss, where size and depth are negatively related. So, why does size decrease in the abyss? One obvious concern is that the pattern could reflect sampling bias. Densities of the macrobenthos as a whole (Rex 1981), and gastropods (Rex et al. 1990, 2005), decrease exponentially with depth and reach very low levels in the abyss. This raises the possibility that larger snails were encountered less often at abyssal depths because of undersampling. However, several lines of evidence suggest that undersampling is not the main underlying cause. First, there are considerably more samples collected in the abyss (17) than for any other major physiographic feature (continental shelf, upper and lower continental slope, and upper and lower continental rise, 2 to 7 samples). The total sample size of the abyss $(\mathrm{N}=1104)$ exceeds that of the entire lower bathyal region between 2000 and $4000 \mathrm{~m}$ $(\mathrm{N}=626)$, where average size is conspicuously higher (Fig. 2). In addition, some of the largest individuals have been recovered from abyssal depths (Fig. 2). Second, abyssal assemblages show very uneven relative abundance distributions that are numerically dominated by 2 species, Benthonella tenella and Xyloskenea naticiformis, which have both abyssal and lower bathyal distributions, but nowhere reach large size (maximum height plus width values are about 7 and $4 \mathrm{~mm}$ respectively; Rex \& Etter 1990, Rex et al. 2002, McClain et al. 2004). In other words, common abyssal species are characteristically small. Third, to determine whether collecting larger individuals is biased by depth of sampling we regressed the partial residuals of the maxi- mum size recorded for each species (with the effect of its depth range midpoint statistically removed) against the number of individuals collected for each species. This relationship is not significant $\left(\mathrm{r}^{2}=0.007, \mathrm{p}=\right.$ $0.4450, \mathrm{df}=79$ ), suggesting that the likelihood of capturing larger individuals is similar across the entire depth range sampled. Still, we caution that there is considerable variation in size trends within and among species (Figs. 2, $3 \& 4$ ), and that only more intensive sampling can establish size-depth trends in a definitive way.

One possible explanation for smaller size in abyssal snails is that bathyal and abyssal zones may function as a source-sink system for populations of some species (Rex et al. 2005). The rate of nutrient input to the deepsea benthos from surface production decreases exponentially with depth across the continental margin and reaches extremely low levels in the abyss far from sources of coastal production and terrestrial runoff. This results in the well known decline in animal density with depth mentioned above (Gage \& Tyler 1991). Species diversity also decreases from the lower bathyal region to the abyss, where standing stock becomes extremely low (Rex 1981, McClain et al. 2004). The abyssal molluscan fauna consists mainly of deeper range extensions for a subset of bathyal species with larval dispersal. Most abyssal populations live at densities that seem too low for successful reproduction. The abyss may be an unfavorable sink environment where many molluscan populations are reproductively unsustainable and are maintained by immigration from bathyal sources (Rex et al. 2005). Even the few common, and presumably more successful, abyssal species like Benthonella tenella and Xyloskenea naticiformis are small, suggesting that the extremely low productivity of this region acts as a biogeographic filter favoring small size. If this scenario is correct, then reduced body size at abyssal depths likely reflects unfavorable circumstances for growth. In other words, a greater proportion of abyssal individuals remain relatively small either because they are immature or belong to inherently small taxa. Many species simply run out of energy for growth and reproduction as Thiel (1975, 1979) suggested. The severe energy constraints on population growth and reproductive success of some species ultimately depress abyssal species diversity. Or, as Hutchinson (1959, p. 150) said for a different environment, 'the rarer species in a community may be so rare that they do not exist'.

Acknowledgements. We thank B. Boyle, R. Etter, J. Brown, C. Stuart, and 3 anonymous reviewers for reading the manuscript and for their helpful comments. R. Etter also provided advice on the statistical analysis and interpretation. R. Costello assisted with imaging systems and software, and A. Warén with gastropod taxonomy. Maria Mahoney helped 
prepare the manuscript. This research is funded by National Science Foundation grants GER-9552836 and OCE-0135949 to M.A.R.

\section{LITERATURE CITED}

Brown JH (1995) Macroecology. University of Chicago Press, Chicago, IL

Cade BS, Noon BR (2003) A gentle introduction to quantile regression for ecologists. Front Ecol Environ 1:412-420

Cade BS, Terrel JW, Schroeder RL (1999) Estimating effects of limiting factors with regression quantiles. Ecology 80: 311-322

Chapelle G, Peck LS (1999) Polar gigantism dictated by oxygen availability. Nature 399:114-115

Chase MR, Etter RJ, Rex MA, Quattro JM (1998) Bathymetric patterns of genetic variation in a deep-sea protobranch bivalve, Deminucula atacellana. Mar Biol 131:301-308

Clain AJ, Rex MA (2000) Size-depth patterns in two bathyal turrid gastropods: Benthomangelia antonia (Dall) and Oenopota ovalis (Friele). Nautilus 114:93-98

Etter RJ, Rex MA (1990) Population differentiation decreases with depth in deep-sea gastropods. Deep-Sea Res 37: 1251-1261

Etter RJ, Rex MA, Chase MR, Quattro JM (2005) Population differentiation decreases with depth in deep-sea bivalves. Evolution 59 (in press)

Gage JD, Tyler PA (1991) Deep-sea biology: a natural history of organisms at the deep-sea floor. Cambridge University Press, Cambridge

Gillooly JF, Brown JH, West GB, Savage VM, Charnov EL (2001) Effects of size and temperature on metabolic rate. Science 293:2248-2251

Gillooly JF, Charnov EL, West GB, Savage VM, Brown JH (2002) Effects of size and temperature on developmental time. Nature 417:70-73

Harasewych MG, Kantor YI (2004) The deep-sea Buccinoidea (Gastropoda: Neogastropoda) of the Scotia Sea and adjacent abyssal plains and trenches. Nautilus 118:1-42

Hessler RR, Sanders HL (1967) Faunal diversity in the deep sea. Deep-Sea Res 14:65-78

Hutchinson GE (1959) Homage to Santa Rosalia, or why are there so many kinds of animals. Am Nat 93:145-159

Jumars PA, Wheatcroft RA (1989) Responses of benthos to changing food qualtity and quantity, with a focus on deposit feeding and bioturbation. In: Berger WH, Smetacek VS, Wefer G (eds) Productivity of the ocean: past and present. Wiley, New York, p 235-253

Lampitt RS, Billet DSM, Rice AL (1986) Biomass of the invertebrate megabenthos from $500-4100 \mathrm{~m}$ in the northeast Atlantic Ocean. Mar Biol 93:69-81

Levinton JS (1987) The body size-prey size hypothesis and Hydrobia. Ecology 68:229-231

McClain CR, Rex MA (2001) The relationship between dissolved oxygen concentration and maximum size in deepsea turrid gastropods: an application of quantile regression. Mar Biol 139:681-685

McClain CR, Rex MA, Johnson N (2004) Morphological disparity as a biodiversity metric in lower bathyal and abyssal gastropod assemblages. Evolution 58:338-348

McClain CR, Rex MA, Etter RJ (2005) Deep-sea macroecology. In: Witman JD, Roy K (eds) Marine macroecology. University of Chicago Press, Chicago, IL (in press)

Olabarria C, Thurston MH (2003) Latitudinal and bathymetric trends in body size of the deep-sea gastropod Troshelia berniciensis (King). Mar Biol 143:723-730

Peters RH (1983) The ecological implications of body size. Cambridge University Press, Cambridge

Polloni P, Haedrich R, Rowe G, Clifford CH (1979) Size-depth relationship in deep ocean animals. Int Rev Gesamten Hydrobiol 64:39-46

Rex MA (1976) Biological accommodation in the deep-sea benthos: comparative evidence on the importance of predation and productivity. Deep-Sea Res 23:957-987

Rex MA (1977) Zonation in deep-sea gastropods: the importance of biological interactions to rates of zonation. Eur Symp Mar Biol 11:521-530

Rex MA (1981) Community structure in the deep-sea benthos. Annu Rev Ecol Syst 12:331-353

Rex MA, Etter RJ (1990) Geographic variation in two deepsea gastropods, Benthonella tenella (Jeffreys) and Benthomangelia antonia (Dall). Deep-Sea Res 37:1229-1249

Rex MA, Etter RJ (1998) Bathymetric patterns of body size: implications for deep-sea biodiversity. Deep-Sea Res II 45: 103-127

Rex MA, Warén A (1982) Planktotrophic development in deep-sea prosobranch snails from the western North Atlantic. Deep-Sea Res 29:171-184

Rex MA, Etter RJ, Nimeskern PW Jr (1990) Density estimates for deep-sea gastropod assemblages. Deep-Sea Res 37 : 555-569

Rex MA, Etter RJ, Clain AJ, Hill MS (1999) Bathymetric patterns of body size in deep-sea gastropods. Evolution 53: 1298-1301

Rex MA, Bond A, Etter RJ, Rex AC, Stuart CT (2002) Geographic variation of shell geometry in the abyssal snail $X Y$ loskenea naticiformis (Jeffreys, 1883). Veliger 45:218-223

Rex MA, McClain CR, Johnson NA, Etter RJ, Allen JA, Bouchet P, Warén A (2005) A source-sink hypothesis for abyssal biodiversity. Am Nat 162:163-178

Roy K (2002) Bathymetry and body size in marine gastropods: a shallow water perspective. Mar Ecol Prog Ser 237:143-149

Sanders HL (1977) Evolutionary ecology of the deep-sea benthos. In: Goulden CE (ed) The changing scenes in natural sciences: 1776-1976. Special Publication, Academy of Natural Sciences, Pennsylvania, PA, p 223-243

Sanders HL, Hessler RR, Hampson GR (1965) An introduction to the study of the deep-sea benthic faunal assemblages along the Gay Head-Bermuda transect. Deep-Sea Res 12:845-867

Savage VM, Gillooly JF, Woodruff WH, West GB, Allen AP, Enquist BJ, Brown JH (2004) The predominance of quarter-power scaling in biology. Funct Ecol 18:257-282

Scharf FS, Juanes F, Sutherland M (1998) Inferring ecological relationships from the edges of scatter diagrams: comparison of regression techniques. Ecology 79:448-460

Sebens KP (1982) The limits to indeterminate growth: an optimal size model applied to passive suspension feeders. Ecology 63:209-222

Sebens KP (1987) The ecology of indeterminate growth in animals. Annu Rev Ecol Syst 18:371-407

Spight TM (1976) Ecology of hatching size for marine snails. Oecologia 24:283-294

Thiel H (1975) The size structure of the deep-sea benthos. Int Rev Ges Hyrdobiol 60:575-606

Thiel H (1979) Structural aspects of the deep-sea benthos. Ambio Spec Rep 6:25-31

Van Voorhies WA (1996) Bergmann size clines: a single explanation for their occurrence in ectotherms. Evolution 50:1259-1264

Submitted: November 10, 2004; Accepted: March 31, 2005

Proofs received from author(s): July 7, 2005 